\title{
Inegy - effective combination treatment to target LDL-C levels
}

\author{
Katherine Croom \\ CSF Medical Communications, Cheltenham, UK
}

Drugs in Context

DOI: http://dx.doi.org/10.7573/dic.212217

Citation: Croom, K. Inegy - effective combination treatment to target LDL-C levels. Drugs in Context: e212217. doi:10.7573/dic.212217

Copyright: this is an open access article published under the terms of the Creative Commons License Deed (CG BY-NG-ND 3.0) which allows you to share, copy, distribute and transmit the work provided it is properly attributed. You may not use this work for commercial purposes. For further information on commercial use, contact publisher@justmedicalmedia.com or go to wrew.drugsincontext.com/copyright.

Search criteria: English language articles were identified by searching the PubMed database using the search terms 'ezetimibe' and 'simvastatin'. Abstracts were evaluated and selected for further review according to our standard protocols. Bibliographies of individual articles were also assessed for additional articles of interest and the manufacturer of Inegy was contacted and was invited to supply any additional data to that identified via the PubMed database.

Date of last literature search: 13 September 2007.

Conclusion: Inegy's dual mechanism of action can provide greater reductions in plasma LDL-C levels in patients with dyslipidaemia than statins alone, allowing more patients to reach their target LDL-C level.

NB: This article was originally published by CSF Medical Communications Ltd (CSF) in Drugs in Context 2008;4(1):41-58. Drugs in Context and all CSF copyrights were acquired by Just Medical Media Ltd in 2009. 


\section{SUMMARY}

Aggressive lipid lowering can improve cardiovascular outcomes, particularly among high-risk patients. However, many patients fail to achieve increasingly stringent LDL-C goals when treated in clinical practice. Consequently, novel approaches to lipid management are required. Inegy (Vytorin in the USA) combines two lipid-modifying drugs, ezetimibe and simvastatin, which have complementary mechanisms of action. By inhibiting two independent pathways of plasma cholesterol generation - the exogenous pathway of cholesterol absorption from the gut (via ezetimibe) and the endogenous pathway of cholesterol biosynthesis in the liver (via simvastatin) - Inegy reduces plasma LDL-C levels and also improves other elements of the lipid profile. A number of clinical studies have consistently demonstrated that Inegy provides more potent LDL-C lowering than statin monotherapy. Indeed, the reductions in LDL-C associated with low-dose Inegy appear to be similar to those achieved by monotherapy with maximum doses of even the most potent statins. Thus, Inegy reduces the need for statin dose titration, potentially reducing the adverse events associated with high-dose statin monotherapy. Moreover, the safety and tolerability profile of Inegy appears to be similar to low-dose statin monotherapy. These findings suggest that Inegy represents a useful addition to the lipid management strategies that are currently available to clinicians.

Key words: ezetimibe; simvastatin; Inegy; Vytorin; dyslipidaemia; hyperlipidaemia.

\section{DYSLIPIDAEMIA: A PERSPECTIVE}

Raised levels of LDL-C and total cholesterol are well-established risk factors for the development of cardiovascular disease. The risk of coronary heart disease (CHD) - one of the main components of cardiovascular disease - increases with increasing plasma cholesterol levels, with a log-linear relationship apparent between plasma levels of LDL-C and the relative risk for CHD. ${ }^{1}$ Conversely, cardiovascular risk is inversely related to levels of high density lipoprotein cholesterol (HDL-C). Cardiovascular disease continues to be the major cause of mortality, and is responsible for about $36 \%$ of all deaths in the UK alone. ${ }^{2}$

In the USA, 1 in 3 of the population have one or more cardiovascular diseases, with an overall cost estimated at almost \$US432 billion in 2007. ${ }^{3}$

Statins are the most widely used drugs for modifying the atherogenic lipid profile for patients with hypercholesterolaemia. A number of landmark studies have elegantly demonstrated that changes to the lipid profile elicited by longterm statin treatment translate to real benefits in terms of cardiovascular outcomes. ${ }^{4,5}$
Despite the established efficacy of statins for improving lipid profiles and reducing cardiovascular risk, as many as $60 \%$ of patients fail to meet LDL-C goals set out in various national and international cholesterol management guidelines ${ }^{6,7}$ The most recent guidelines from the National Cholesterol Education Program (NCEP) in the USA have established even more stringent LDL-C goals, particularly for patients with established CHD or in those with CHD risk equivalents, such as those with type 2 diabetes. ${ }^{7}$ As the evidence base continues to support increasingly aggressive lipid lowering, particularly in very high-risk patients (i.e. those suffering acute cardiovascular events or with existing cardiovascular disease plus other risk factors), the NCEP guidelines have been modified to indicate that it is reasonable to aim for a new optional lower target of under 70 $\mathrm{mg} / \mathrm{dL}$ (equivalent to $1.8 \mathrm{mmol} / \mathrm{L}^{\mathrm{a}}$ ) for such patients. ${ }^{1}$ In patients failing to achieve target

${ }^{a}$ Throughout this review we have reported cholesterol concentrations (including US guideline targets) in SI units. 
LDL-C levels, clinicians may opt to switch or increase the dose of statin, which could deliver an additional reduction in LDL-C of $8 \%$ and $6 \%{ }^{8}$

However, several factors may explain why so many people fail to attain treatment targets. ${ }^{9}$ Firstly, patient adherence to treatment remains poor, not least because hypercholesterolaemia is a predominantly asymptomatic and chronic condition, but also because some patients experience minor side- effects with statin use (e.g. gastrointestinal disturbances). Secondly, physicians are often reluctant to increase the dose of lipid-lowering drugs because of safety concerns regarding higher drug doses in particular because the frequency of adverse events increases more than efficacy does as dosages increases. ${ }^{10}$ Finally, combination therapy as an alternative to highdose statin monotherapy is often under-used in clinical practice, primarily because of concerns about drug interactions and major adverse events. This is probably best illustrated by the increased risk of myopathy and potentially fatal rhabdomyolysis associated with the combination of a statin and the fibrate gemfibrozil. ${ }^{9}$

Alternative lipid-modifying agents are available which have distinct and complementary mechanisms of action to the statins. Ezetimibe is one such treatment, acting to selectively inhibit dietary and biliary cholesterol absorption across the wall of the small intestine, thereby reducing delivery of intestinal cholesterol to the liver (Figure 1). ${ }^{8,11}$ By combining ezetimibe with a statin, both the exogenous and endogenous pathways of cholesterol generation are inhibited, resulting in greater reductions in cholesterol levels compared with statin or ezetimibe monotherapy (Figure 1). ${ }^{12}$ Therefore, by combining a statin with ezetimibe, the requirement for statin dose titration can be reduced, thereby minimising the likelihood of dose-related adverse events.

Inegy is a fixed-dose combination product that combines ezetimibe $(10 \mathrm{mg})$ with varying doses of simvastatin (20, 40 and $80 \mathrm{mg}$ ) in a
Figure 1. The dual mechanism of action of Inegy.

Ezetimibe inhibits the exogenous pathway of cholesterol generation by preventing absorption of cholesterol from the gut, whilst simvastatin inhibits the endogenous pathway by preventing cholesterol biosynthesis in the liver. ${ }^{6}$

ApoB, apolipoprotein; CM, chylomicron; LDL, low-density lipoprotein cholesterol; VLDL, very low-density lipoprotein cholesterol.

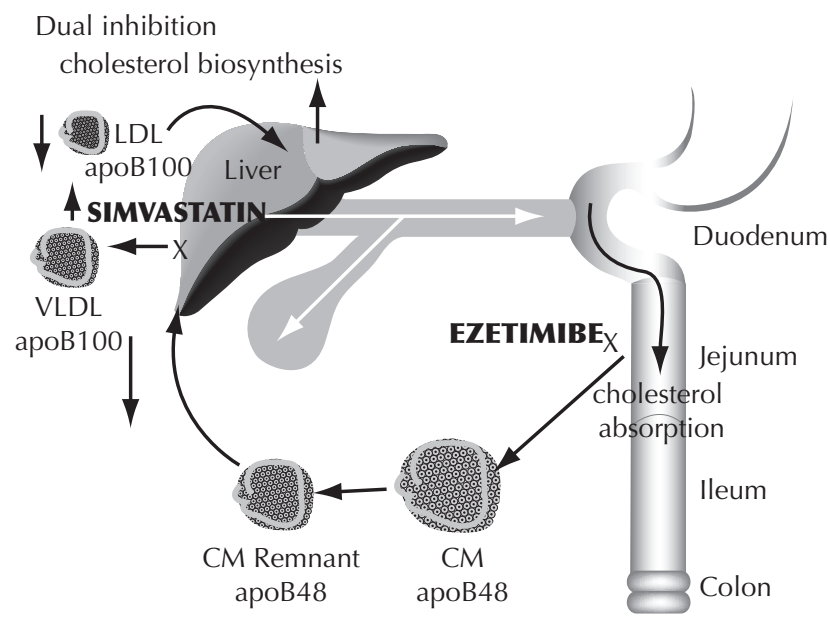

single tablet. Administration of a single tablet has the potential to enhance patient adherence to treatment, and may further improve treatment outcomes. Ezetimibe is the subject of a separate Drugs in Context - Drug Profile, which provides more detailed information regarding monotherapy with ezetimibe. ${ }^{13}$ The present review of Inegy examines the clinical and pharmacological evidence that has accumulated for ezetimibe in combination with simvastatin, whether given as a single fixed-dose tablet (Inegy) or as separate drugs given concurrently.

\section{PHARMACOLOGY}

As Inegy is bioequivalent to its individual components administered concurrently, ${ }^{9,14}$ it is reasonable to briefly consider the basic pharmacological characteristics of the individual components of the product rather than focus on the combination per se. 


\section{Mechanism of action}

The individual components of Inegy - ezetimibe and simvastatin - act through two distinct and complementary mechanisms to reduce plasma cholesterol levels. Ezetimibe and its active glucuronidated metabolite localise to the brush border of the small intestine and are thought to block the actions of a cholesterol transport protein, which until recentlywas believed to be the Niemann-Pick C1 Like 1 protein [NPC1L1]). ${ }^{15}$ However, recent knock-out experiments in mice have challenged the prevailing belief that NPG1L1 facilitates intestinal cholesterol uptake into the brush border membrane and that the inhibition of NPC1L1 by ezetimibe is responsible for the inhibition of this process. ${ }^{16}$ Although the mechanism of action remains to be fully elucidated, the net effect of ezetimibe therapy is to inhibit the absorption of dietary and biliary cholesterol across the intestinal wall (by about 50\%) without affecting the absorption of triglycerides, fatty acids, bile acids, progesterone and ethinyl estradiol, or fat-soluble vitamins. ${ }^{9}$ Consequently, delivery of cholesterol to the liver is reduced, resulting in a reduction in hepatic cholesterol stores and an increase in cholesterol clearance from the circulation. ${ }^{17}$

In contrast, simvastatin (after metabolic activation in the liver) inhibits the early and ratelimiting step of cholesterol biosynthesis in the liver via reversible inhibition of the 3-hydroxy3-methylglutaryl coenzyme A (HMG-CoA) reductase enzyme. ${ }^{9}$ Thus, simvastatin blocks endogenous cholesterol production in the liver leading to a reduction in both normal and elevated levels of LDL-C in plasma. Moreover, this inhibitory effect on plasma levels of LDL-C promotes an up-regulation of the expression of LDL receptors on hepatocytes, further clearing LDL particles from the circulation. This is thought to be the main mechanism by which simvastatin reduces LDL-C levels. ${ }^{9}$
Simvastatin may also increase the clearance of very low density lipoproteins (VLDL) and intermediate density lipoproteins (IDL) before their conversion to LDL. ${ }^{9}$ It is known that inter-individual variations in cholesterol absorption and biosynthesis occur; in addition, upregulation of cholesterol absorption can take place during statin therapy. ${ }^{18}$ Combination therapy with ezetimibe and simvastatin provides a dual approach covering both high and low cholesterol synthesizers and high and low cholesterol absorbers.

\section{Pharmacokinetics}

Co-administration of ezetimibe with simvastatin has no effect on the pharmacokinetic characteristics of simvastatin. ${ }^{19,20}$ In addition, ezetimibe does not have significant effects on plasma levels of any other statins (atorvastatin, fluvastatin, lovastatin, pitavastatin, pravastatin or rosuvastatin), fibric acid derivatives (gemfibrozil or fenofibrate), digoxin, glipizide, warfarin and triphasic oral contraceptives (ethinyl estradiol and levonorgestrel).$^{19}$ However, co-administration of Inegy and fibrates is not, as yet, recommended. ${ }^{17}$ Concomitant administration of food, antacids, cimetidine or statins has no significant effect on ezetimibe bioavailability, and though food has no effect on the absorption of either drug, the peak plasma concentration of ezetimibe is increased by about $40 \%$ after consumption of a high-fat meal. ${ }^{17,19}$

The principal pharmacokinetic parameters of ezetimibe, its glucuronidated metabolite and simvastatin are summarised in Table $1 .{ }^{11,17}$ Ezetimibe is rapidly absorbed and undergoes rapid and extensive glucuronidation in the intestine and liver to form the active metabolite. ${ }^{11,17}$ Peak plasma concentrations are reached 1-2 hours after dosing for the glucuronidated metabolite and after 4-12 hours for the parent compound, which has a long terminal half-life that allows once-daily 
Table 1. The pharmacokinetic characteristics of ezetimibe, its glucuronidated metabolite, and simvastatin. ${ }^{11,17}$

\begin{tabular}{lccc}
\hline Pharmacokinetic parameter & ezetimibe & ezetimibe-glucuronide & simvastatin \\
\hline Volume of distribution (L) & $105-107.5$ & - & - \\
$\mathrm{t}_{\max }$ (hours) & $4-12$ & $1-2$ & $1-2$ \\
$\mathrm{t}_{1 / 2}($ hours) & $\sim 22$ & $\sim 22$ & 1.9 \\
$\mathrm{~A} \cup \mathrm{C}(\mathrm{mg} / / \mathrm{hour})$ & - & 10 & - \\
$\mathrm{C}_{\max }(\mu \mathrm{g} / \mathrm{L})$ & $70.6-79.3$ & 2.6 & - \\
Protein binding $(\%)$ & 99.7 & $88-92$ & 95 \\
Metabolism & Glucuronidation & - & $\mathrm{CYP} 3 \mathrm{~A} 4$ \\
Elimination in urine/faeces $(\%)$ & $11 / 78$ & - & $13 / 60$ \\
\hline
\end{tabular}

$\mathrm{A} \cup \mathrm{C}$, area under the concentration-time curve; $\mathrm{C}_{\text {max }}$ peak plasma concentration; $\mathrm{t}_{\text {max }}$ time to peak plasma concentration; $\mathrm{t}_{1 / 2^{\prime}}$ elimination half-life.

dosing. ${ }^{17,19,21}$ The glucoronidated metabolite represents $80-90 \%$ of absorbed ezetimibe and circulates enterohepatically, being repeatedly delivered back to the intestine, its site of action. ${ }^{9,17}$ Exposure of the drug systemically is therefore limited. Furthermore, ezetimibe is not metabolised by the cytochrome P450 (CYP) system in the liver, and therefore has a low propensity to interact with other drugs. ${ }^{21}$ Simvastatin is administered as a prodrug, which is converted into the active $\alpha$-hydroxyacid form via extensive first-pass metabolism in the liver by the CYP 3A4 isoenzyme. ${ }^{21,22}$ Given its interaction with CYP 3A4, simvastatin (and Inegy) may interact with other drugs and substances metabolised by this isoenzyme. Peak plasma concentrations of active simvastatin metabolites occur approximately 2 hours after oral dosing. ${ }^{21}$ There do not appear to be any clinically significant pharmacokinetic differences requiring dose changes when Inegy is given to elderly patients. ${ }^{17}$

\section{Dosing}

Inegy is a fixed-dose single tablet combination of ezetimibe and simvastatin, available as three different dosages all of which contain ezetimibe, $10 \mathrm{mg}$, and simvastatin (either 20, 40 or 80 $\mathrm{mg}) \cdot{ }^{17}$ As such, the different dosages of Inegy are described throughout this review as 10/20, $10 / 40$ and $10 / 80 \mathrm{mg}$. A similar format is used to describe dosages for separate tablets administered concurrently (e.g. ezetimibe-simvastatin 10/10 $\mathrm{mg}$. Typical doses of Inegy in clinical practice are $10 / 20$ and $10 / 40 \mathrm{mg}$, given as a single dose in the evening. The maximum dose of Inegy $(10 / 80 \mathrm{mg})$ is normally reserved for patients with severe hypercholesterolaemia and for those at high risk of cardiovascular complications. ${ }^{17}$ In the USA (trade name Vytorin) the combination tablet is also available at a dosage of 10/10 mg.

\section{CLINICAL EFFICACY}

A number of studies have evaluated the lipidmodifying effects of Inegy. In general terms, Inegy therapy provides substantial additional reductions in LDL-G compared with statin monotherapy, which thus allows more patients to achieve their LDL-G goals. Here, we will discuss studies that evaluated the combination of ezetimibe and simvastatin, either given concurrently as two separate tablets, or in a fixed-dose combination (i.e. Inegy). Only the single-tablet formulation will be referred to as Inegy. If the drugs were co-administered as separate tablets (or if it is unclear which formulation was administered) the term 'ezetimibe-simvastatin' will be used.

\section{Inegy vs simvastatin monotherapy: dose-ranging studies}

A number of controlled clinical trials have evaluated the lipid-modifying effects of Inegy relative to simvastatin monotherapy administered 
across their respective dose ranges over 12 weeks to patients with primary hypercholesterolaemia (LDL-G $\geq 3.75 \mathrm{mmol} / \mathrm{L}$ and $<6.5 \mathrm{mmol} / \mathrm{L}$; triglycerides $\leq 3.95 \mathrm{mmol} / \mathrm{L}) .{ }^{23-25}$ The changes to major components of patients' lipid profiles, pooled across the respective dosages of Inegy and simvastatin is shown in Table $2 .{ }^{23-25}$ All three studies used a factorial design and the primary analyses were based on a comparison of pooled data for all doses within each treatment group.

In a double-blind study of 668 patients randomised to 12 weeks' treatment with simvastatin $(10,20,40$ or $80 \mathrm{mg} /$ day), ezetimibe monotherapy $(10 \mathrm{mg})$, a combination of both drugs at four different doses (i.e. ezetimibesimvastatin, 10/10, 10/20, 10/40 and 10/80 $\mathrm{mg}$ ), or placebo, the addition of ezetimibe to simvastatin led to a $13.8 \%$ additional reduction in LDL-C compared with simvastatin monotherapy (data pooled across the four different doses of simvastatin; $p<0.01$ [Table 2]). ${ }^{23}$ Across the ezetimibe-simvastatin dose range, combination therapy was associated with a $44-57 \%$ reduction in LDL-C compared with a $27-44 \%$ reduction with simvastatin, 10-80 mg (Figure 2). The incremental reductions in LDL-C afforded by the addition of ezetimibe to simvastatin therapy were significant when compared with the milligram equivalent dosage of simvastatin $(p<0.01)$ or a doubling in the dosage of simvastatin monotherapy (Figure 2). Moreover, Inegy at its lowest dose (10/10 mg) was associated with an equivalent reduction in LDL-C as that afforded by the highest dose (80 $\mathrm{mg}$ ) of simvastatin monotherapy (reductions from baseline of $44 \%$ in both groups [Figure 2]). This suggests that ezetimibe-simvastatin reduces the need to titrate the statin dose in patients not responding to lower dose statin therapy. In addition, combination therapy (pooled across the different dosages) was associated with an extra $7.4 \%$ reduction in levels of triglycerides $(p<0.01)$ and a $2.4 \%$ increase in HDL-C $(p=0.03)$ when compared with statin monotherapy (see Figure 3 for changes at each milligram dosage). The reductions in LDL-C reported in this study allowed more patients in the ezetimibe-simvastatin treatment arms to achieve their NCEP ATP-III LDL-C goals than those who received simvastatin monotherapy after 12 weeks of therapy (77 vs 64\%; $p<0.01$ ). Other elements of the lipid profile (i.e. total cholesterol, non-HDL-C, apolipoprotein B and apolipoprotein A-I) were also improved by

Table 2. Summary of lipid-modifying effects and attainment of National Cholesterol Education Program Adult Treatment Panel III LDL-C goals (data pooled for all doses within each treatment group) from clinical trials of patients with primary hypercholesterolaemia. ${ }^{23-25}$

\begin{tabular}{|c|c|c|c|c|c|}
\hline \multirow[t]{2}{*}{ Study } & \multirow{2}{*}{$\begin{array}{l}\text { Treatment } \\
\text { regimen }\end{array}$} & \multicolumn{3}{|c|}{$\begin{array}{c}\text { Percentage change from baseline }(\%) \\
\end{array}$} & \multirow{2}{*}{$\begin{array}{l}\text { Patients achieving } \\
\text { NCEP ATP-III } \\
\text { LDL-C goals ( } \%)\end{array}$} \\
\hline & & LDL-C & HDL-C & $\overline{\text { Triglycerides }}$ & \\
\hline \multirow[t]{2}{*}{ Davidson et al., 2002. ${ }^{23}$} & Eze-sim (10/10-10/80 mg) & $-49.9^{a}$ & $+9.3^{\mathrm{b}}$ & $-24.1^{\mathrm{a}}$ & $77^{\mathrm{a}}$ \\
\hline & Simvastatin (10-80 mg) & -36.1 & +6.9 & -16.6 & 64 \\
\hline \multirow[t]{2}{*}{ Goldberg et al., 2004. ${ }^{25}$} & Eze-sim (10/10-10/80 mg) & $-53.2^{\mathrm{c}}$ & +8.2 & $-28.0^{c}$ & $82^{\mathrm{c}}$ \\
\hline & Simvastatin (10-80 mg) & -38.5 & +7.6 & -15.2 & 43 \\
\hline \multirow[t]{2}{*}{ Bays et al., 2005.24 } & Eze-sim (10/10-10/80 mg) ${ }^{d}$ & $-53.0^{c}$ & +7.2 & $-24.3^{\mathrm{c}}$ & $79^{c}$ \\
\hline & Simvastatin (10-80 mg) & -39.0 & +6.8 & -20.8 & 46 \\
\hline
\end{tabular}

${ }^{\mathrm{a}} \mathrm{p}<0.01$ for Eze-sim vs simvastatin.

${ }^{\mathrm{b}} \mathrm{p}=0.02$ for Eze-sim vs simvastatin.

${ }^{c} \mathrm{p}<0.001$ for Eze-sim vs simvastatin.

Inegy tablet.

Eze-sim, ezetimibe-simvastatin; HDL-C, high density lipoprotein cholesterol; LDL-C, low density lipoprotein cholesterol, i.e. 10/10-10/80 mg; NCEP ATP III, National Cholesterol Education Program Adult Treatment Panel III. 
Figure 2. Percentage changes from baseline in low-density lipoprotein cholesterol (LDL-C), high-density lipoprotein cholesterol (HDL-C) and triglycerides in patients with primary hypercholesterolaemia treated with ezetimibe-simvastatin or simvastatin monotherapy for 12 weeks. $^{23}$
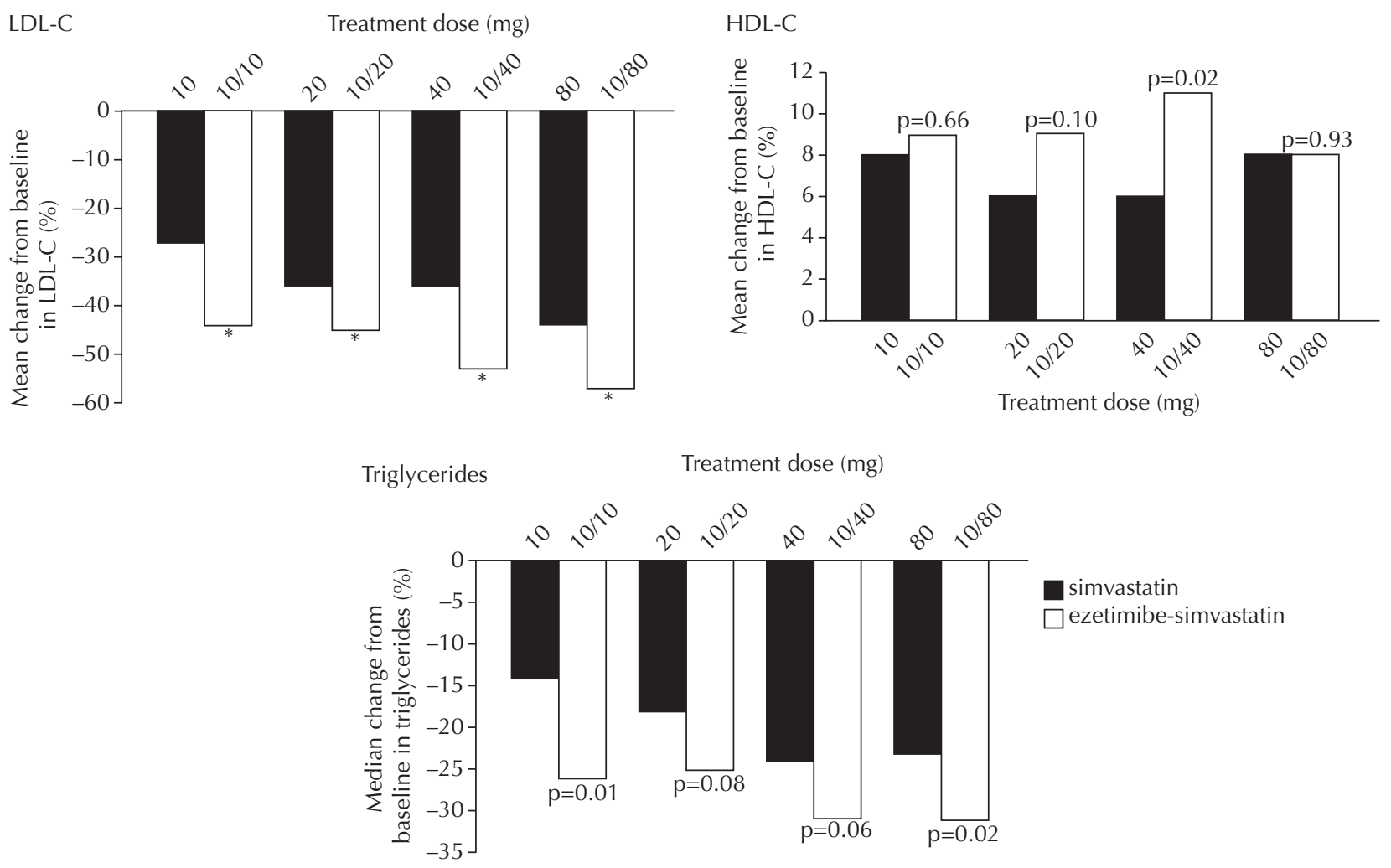

${ }^{*} p<0.01$ for ezetimibe-simvastatin vs simvastatin

a significantly greater extent with ezetimibesimvastatin therapy compared with simvastatin monotherapy. The ezetimibe-simvastatin combination was well tolerated in this study, with a safety profile generally similar to both simvastatin monotherapy and placebo.

Similar results to those reported by Davidson et al. ${ }^{23}$ were obtained in two further doseranging studies, as summarised in Table 2. Of particular note are the results of the large, double-blind, dose-ranging study reported by Bays et al. ${ }^{24}$ A total of 1528 patients with primary hypercholesterolaemia were enrolled to 12 weeks' treatment with one of ten different treatment regimens: Inegy, 10/10, 10/20, 10/40 or $10 / 80 \mathrm{mg} /$ day; simvastatin, $10,20,40$ or 80 $\mathrm{mg} /$ day; ezetimibe, $10 \mathrm{mg} /$ day; or placebo. ${ }^{24}$
With the exception of changes in HDL-C, the effects on other components of the lipid profile were significantly greater with Inegy than with simvastatin monotherapy (Table 2). ${ }^{24}$ Doseby-dose comparisons showed that significantly greater reductions in LDL-C were achieved with Inegy compared with milligram equivalent doses of simvastatin monotherapy and also when compared with the next highest scheduled dose of simvastatin (Figure 3). Levels of the markers of cardiovascular risk, C-reactive protein ( $\mathrm{CRP}$ ) and reminant-like particle-cholesterol (RLP-C), were significantly reduced by a greater extent with Inegy than with simvastatin monotherapy $(p<0.001)$. Inegy was well tolerated in this study, with a similar safety profile as simvastatin monotherapy. 
Figure 3. Mean percentage change from baseline in low-density lipoprotein cholesterol (LDL-C) with Inegy or simvastatin monotherapy, given across their licensed dosages. ${ }^{24}$

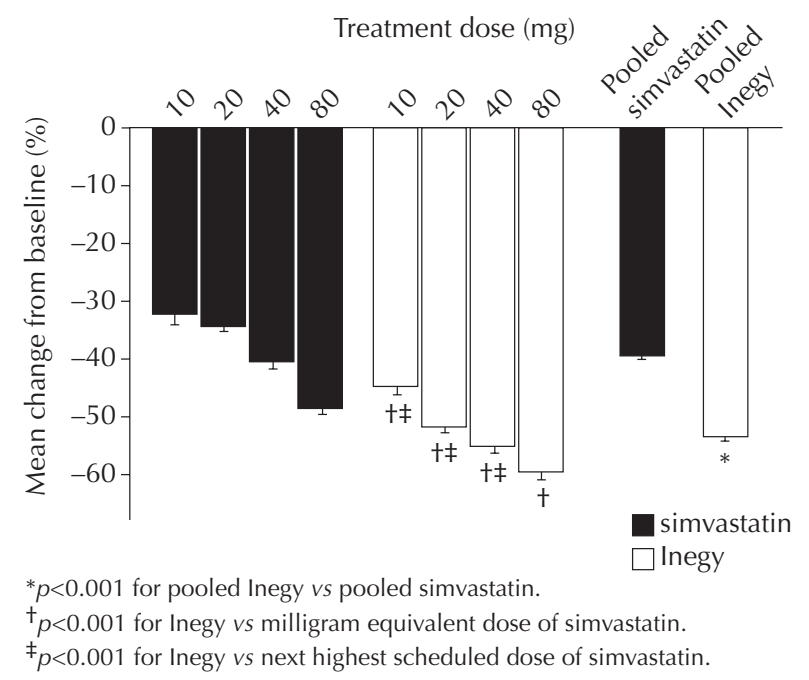

A large clinical outcomes trial (Improved Reduction of Outcomes: Vytorin Efficacy International Trial - IMPROVE IT), is currently underway to compare Inegy and simvastatin monotherapy in patients with stabilised acute coronary syndrome (ACS). The composite endpoint of cardiovascular death, major coronary events and stroke will be used as the primary clinical outcome measure.

\section{LDL-C goal attainment in high-risk patients}

Given the greater LDL-C lowering potency of Inegy relative to simvastatin monotherapy, it is important to determine whether this would translate into superiority regarding high-risk patients (i.e. those with documented CHD or with a $\mathrm{CHD}$ risk equivalent) to achieve the more stringent NCEP ATP-III LDL-G goal of less than $2.6 \mathrm{mmol} / \mathrm{L}$ appropriate for such patients.

Ezetimibe-simvastatin has been compared with simvastatin monotherapy, in a high-risk patient population with baseline LDL-C concentrations equal to or above $3.4 \mathrm{mmol} / \mathrm{L}$, who also met
NCEP criteria for CHD or who had a CHD risk equivalent (e.g. diabetes). ${ }^{26}$ Patients $(n=716)$ were randomised to ezetimibe, $10 \mathrm{mg}$, plus simvastatin, 10,20 or $40 \mathrm{mg}$ (i.e. equivalent to Inegy) or simvastatin alone $(20 \mathrm{mg})$, for a period of 23 weeks. The addition of ezetimibe was blinded in this study. Patients not reaching the LDL-C target of less than $2.6 \mathrm{mmol} / \mathrm{L}$ by weeks 6,12 or 18 , had their dose of simvastatin doubled (in a step-wise fashion) up to a daily maximum of $80 \mathrm{mg}$. Adding ezetimibe to a simvastatin treatment produced greater reductions in LDL-C and allowed more patients to reach their LDL-C target after 5 weeks of treatment $(p<0.001)$ and by the end of the study $(p<0.001)$ than did simvastatin monotherapy. Thus, after 5 weeks of treatment, 75, 83 and $87 \%$ of patients receiving 10, 20 and $40 \mathrm{mg}$ of simvastatin respectively, in combination with ezetimibe, $10 \mathrm{mg}$ (i.e. equivalent to Inegy), had reached their target LDL-C levels, compared with $46 \%$ of patients receiving simvastatin, $20 \mathrm{mg}$, alone $(p<0.001)$. The requirement for simvastatin dose titration was also reduced in the combination groups, with 33, 22 and $12 \%$ of patients receiving ezetimibe co-administered with simvastatin, 10, 20 or $40 \mathrm{mg}$, respectively, requiring upward dose titration, compared with $68 \%$ of patients treated with simvastatin alone. Patients receiving the lowest dose of ezetimibe-simvastatin (10/10 $\mathrm{mg}$ ) had approximately 3.6-times greater odds of attaining their LDL-C goal up to the first titration step than those receiving simvastatin, $20 \mathrm{mg}$. Likewise, patients receiving the higher doses of ezetimibe-simvastatin (10/20 and 10/40 $\mathrm{mg}$ ) were 6.0- and 8.4-times more likely to attain their goal than with simvastatin monotherapy. In summary, ezetimibe-simvastatin is more effective than simvastatin monotherapy in getting high-risk patients to the more stringent NCEP ATP-III LDL-C goal of under $2.6 \mathrm{mmol} / \mathrm{L}$, with a reduced need to dose-titrate the simvastatin component of the combination to achieve this goal.

The observations made in this study have been corroborated and extended by trials in 
patients with $\mathrm{CHD},{ }^{27,28}$ and a post hoc analysis of two trials in high-risk patients (with CHD or CHD risk equivalent such as diabetes). ${ }^{29}$ In a double-blind placebo-controlled study, hypercholesterolaemic patients with $\mathrm{CHD}$ $(\mathrm{n}=418)$, already receiving simvastatin (10 or $20 \mathrm{mg}$ ), were randomised to receive additional ezetimibe, $10 \mathrm{mg}$, or placebo, over 6 weeks. ${ }^{27}$ More than four-times as many patients receiving add-on ezetimibe therapy than those given placebo/simvastatin achieved their LDL-C target of less than or equal to $2.6 \mathrm{mmol} / \mathrm{L}$ than those receiving simvastatin plus placebo (80.4 vs $17.4 \%$; $p<0.001$ ). No significant safety issues were apparent in the combination group, though there was a slight increase in treatmentrelated adverse events in those receiving add-on ezetimibe (7.2 vs $2.4 \% ; p<0.05)$, including a higher incidence of gastrointestinal events and myalgia.

A study comprised of patients with CHD $(\mathrm{n}=372)$ randomised in a double-blind manner to 6 weeks' treatment with either continued therapy with simvastatin, 10 or $20 \mathrm{mg}$, or additional ezetimibe, $10 \mathrm{mg}$ (i.e. equivalent to Inegy), showed that more patients in the ezetimibe-simvastatin group $(74.3 \%)$ than the atorvastatin monotherapy group (16.7\%) met the LDL-C target of less than or equal to $2.6 \mathrm{mmol} / \mathrm{L}(p \leq 0.001) .{ }^{28}$ Moreover, a post hoc analysis of data from two large clinical trials of patients with CHD or with CHD risk-equivalent status (e.g. type 2 diabetes) ${ }^{26,30}$ analysed the proportion of patients meeting two LDL-G targets: LDL-C less than or equal to $2.6 \mathrm{mmol} / \mathrm{L}$ and the new, optional treatment target of less than or equal to $1.8 \mathrm{mmol} / \mathrm{L}$ for very high risk patients. ${ }^{29}$ In this analysis, the proportion reaching either LDL-C less than or equal to $2.6 \mathrm{mmol} / \mathrm{L}$ after 6 weeks was greater for ezetimibe-simvastatin $10 / 10$ and $10 / 20$ $\mathrm{mg}$ vs atorvastatin, $10 \mathrm{mg}$ and for ezetimibesimvastatin $10 / 10,10 / 20$ and $10 / 40 \mathrm{mg}$ vs simvastatin, $20 \mathrm{mg}$ ( $p<0.001$, all comparisons).
Similarly, the proportion of patients achieving LDL-C levels less than or equal to $1.8 \mathrm{mmol} / \mathrm{L}$ was greater for ezetimibe-simvastatin, 10/10 and $10 / 20 \mathrm{mg}$ than atorvastatin, 10mg (20 and $34 \%$ vs $5 \%$, respectively) and greater for ezetimibe-simvastatin 10/10, 10/20 and $10 / 40 \mathrm{mg}$ than with simvastatin, $20 \mathrm{mg}$ (25, 30 and $59 \%$ vs $5 \%$, respectively) [p $\leq 0.001$, all comparisons]. Other data from the atorvastatin comparison are discussed in the next section.

\section{Inegy vs atorvastatin monotherapy}

Two main studies have evaluated the relative efficacy and tolerability of ezetimibe-simvastatin and atorvastatin. ${ }^{30,31}$ The findings of these two studies are summarised in Table 3.30,31 The lipid-modifying effects of ezetimibe-simvastatin have been directly compared with atorvastatin monotherapy (across their respective dose ranges) in a 24-week, randomised, double-blind, forced-titration study involving 788 patients with hypercholesterolaemia. ${ }^{30}$ Patients were stratified according to their baseline LDL-C levels, and were then randomised into three treatment groups (one atorvastatin monotherapy group and two different ezetimibe-simvastatin groups). All patients had their dose of study treatment force-titrated over four separate 6-week treatment intervals. Thus, patients in the atorvastatin group initially received a daily dose of $10 \mathrm{mg}$, which was then titrated in a step-wise fashion every 6 weeks to 20, 40 and $80 \mathrm{mg}$. A second treatment group received a daily dose of ezetimibe-simvastatin (10/10 mg), which was then force-titrated to $10 / 20,10 / 40$ and 10/80 mg, over successive 6-week treatment periods. A third group received a higher ezetimibesimvastatin dose at randomisation $(10 / 20 \mathrm{mg}$, which represents the most likely starting dosage in clinical practice), which was subsequently titrated to $10 / 40 \mathrm{mg}$ and maintained at this dose for two consecutive treatment periods (12 weeks), followed by titration to $10 / 80 \mathrm{mg}$ for the final 6 -week period. After 6 weeks of treatment, the 
mean reductions in LDL-C from baseline were significantly greater with Inegy, 10/10 and 10/20 $\mathrm{mg}$, compared with atorvastatin, $10 \mathrm{mg}$ (46.1, 50.3 and $37.2 \%$, respectively; both ezetimibesimvastatin groups $p \leq 0.001$ vs atorvastatin). By the end of the study, the reductions in LDL-C observed in patients receiving the highest dose of Inegy (10/80 mg) exceeded the reductions elicited by the highest dose of atorvastatin (59.4 vs 52.5\%; $\mathrm{p}<0.001)$. Across the dose ranges evaluated in this study, the reductions in LDL-C averaged 52.4\%, some $7.3 \%$ greater than that achieved with the highest dose of atorvastatin (Table 3). The superiority of ezetimibe-simvastatin in reducing LDL-C was also reflected in changes to the HDL-C fraction (Table 3). Data from this study were included in the post hoc analysis of high-risk patients discussed in the previous section. ${ }^{29}$ All treatments were well tolerated in this study with a similar incidence of drug-related adverse events and discontinuations in all treatment groups. In conclusion, co-administration of ezetimibe and simvastatin elicited greater improvements in both LDL-C and HDL-C levels than atorvastatin monotherapy.

A large parallel-group, double-blind randomised controlled trial also investigated the relative efficacy of Inegy and atorvastatin, administered across their licensed dose ranges to a broad range of dyslipidaemic patients $(n=1902)$, of whom nearly $50 \%$ had established $\mathrm{CHD}$ or a CHD risk equivalent in the Vytorin versus Atorvastatin Study (or VYVA). ${ }^{31}$ Patients were randomised to eight treatment groups (Inegy, 10/10, 10/20, 10/40, or 10/80 mg; atorvastatin, 10, 20, 40 or $80 \mathrm{mg}$ ). Treatment was administered over a 6 -week period. When averaged across the dose range of both drugs (i.e. Inegy, 10/10-80 mg/day; atorvastatin, 10-80 mg/day), LDL-C levels were reduced by a greater extent with Inegy than with atorvastatin (mean reduction from baseline: 53.4 vs 45.3\%, respectively; $p<0.001$ [Table 3]). Likewise, when milligram equivalent dosages were compared (i.e. Inegy, 10/10 mg vs atorvastatin, $10 \mathrm{mg}$ ), LDL-C levels were lowered by a significantly greater margin by Inegy $(45-59 \%)$ than atorvastatin (36-53\%). Increases in the HDL-C fraction were also greater in the Inegy, 10/40 and 10/80 mg groups, than in the atorvastatin, 40 and $80 \mathrm{mg}$ groups, whilst reductions in triglycerides were equivalent in each treatment group, with no significant differences observed between the two treatment strategies. Moreover, when averaged

Table 3. Summary of lipid-modifying effects and attainment of low-density lipoprotein cholesterol (LDL-C) goals (data pooled across all ezetimibe-simvastatin and atorvastatin dosage regimens) from clinical trials of patients with primary hypercholesterolaemia. ${ }^{30,31}$

\begin{tabular}{|c|c|c|c|c|c|}
\hline \multirow[t]{2}{*}{ Study } & \multirow{2}{*}{$\begin{array}{l}\text { Treatment } \\
\text { regimen }\end{array}$} & \multicolumn{3}{|c|}{ Percentage change from baseline (\%) } & \multirow{2}{*}{$\begin{array}{c}\text { Patients achieving } \\
\text { NCEP ATP-III } \\
\text { LDL-C goals }(\%)\end{array}$} \\
\hline & & LDL-C & HDL-C & Triglycerides & \\
\hline \multirow[t]{2}{*}{ Ballantyne et al., $2004 .{ }^{30}$} & $\begin{array}{l}\text { eze-sim (force-titrated } \\
\text { from } 10 / 10 \text { to } 10 / 80 \mathrm{mg} \text { ) }\end{array}$ & $-52.4^{a}$ & $+9.5^{b}$ & Not reported ${ }^{c}$ & Not reported \\
\hline & $\begin{array}{l}\text { atorvastatin (force-titrated } \\
\text { from } 10 \text { to } 80 \mathrm{mg} \text { ) }\end{array}$ & -45.1 & +6.2 & Not reported ${ }^{c}$ & Not reported \\
\hline \multirow[t]{2}{*}{ Ballantyne et al., 2005. ${ }^{31}$} & Inegy (10/10-10/80 mg) & $-53.4^{\mathrm{a}}$ & $+7.9^{\mathrm{a}}$ & -27.4 & $89.7^{\mathrm{a}}$ \\
\hline & atorvastatin $(10 / 80 \mathrm{mg})$ & -45.3 & +4.3 & -25.5 & 81.1 \\
\hline
\end{tabular}

${ }^{\mathrm{a}} p<0.001$ for Inegy $v s$ atorvastatin.

${ }^{\mathrm{b}} p=0.002$ for Inegy vs atorvastatin.

cPooled data from all Inegy and atorvastatin groups for triglycerides were not reported, but the authors stated that changes in triglycerides between groups were not significant.

eze-sim, ezetimibe-simvastatin; HDL-C, high density lipoprotein cholesterol; LDL-C, low density lipoprotein cholesterol; NCEP ATP III, National Cholesterol Education Program Adult Treatment Panel III. 
across all doses, $89.7 \%$ of patients achieved their NCEP ATP-III LDL-C goal with Inegy compared with $81.1 \%$ with atorvastatin $(p<0.001$ [Table 3]). Furthermore, in a post hoc analysis, more patients in the Inegy than the atorvastatin group achieved the new optional LDL-C goal for very high-risk patients of under $1.8 \mathrm{mmol} / \mathrm{L}(43.5$ os $20.5 \%$, respectively; $p<0.001$; data averaged across all doses). All treatment regimens were generally well tolerated. More patients receiving atorvastatin than Inegy experienced elevations in liver transaminases, though no myopathy or liver-related adverse events led to discontinuation from the study. In summary, the VYVA study has demonstrated that Inegy provides greater reductions in LDL-C across the dose range and with milligram equivalent doses compared with atorvastatin monotherapy.

\section{Inegy vs rosuvastatin monotherapy}

A double-blind, 6-week, parallel-group study in hypercholesterolaemic patients $(n=2959)$ has assessed the lipid-altering efficacy and safety of Inegy (given as a single tablet) compared with rosuvastatin at the approved usual starting, next highest, and maximum doses. ${ }^{32}$ Patients were randomised based on stratification by LDL-C levels to Inegy or rosuvastatin treatments at the usual starting $(10 / 20 \mathrm{mg}$ or $10 \mathrm{mg}$, respectively), the next highest $(10 / 40 \mathrm{mg}$ or 20 $\mathrm{mg}$, respectively), and maximum doses (10/80 $\mathrm{mg}$ or $40 \mathrm{mg}$, respectively). At all doses and across doses, Inegy reduced LDL-C levels by $52-61 \%$, which was more than with rosuvastatin $(46-57 \% ; \quad p \leq 0.001)$. Significantly greater percentages of all patients $(p<0.001)$ and highrisk patients $(p \leq 0.005)$ attained LDL-C levels less than $1.8 \mathrm{mmol} / \mathrm{L}$ following Inegy treatment compared with rosuvastatin at the pre-specified doses and across doses. Inegy also produced greater reductions in total cholesterol $(p<0.001)$, non-HDL-G $(p<0.001)$ and apolipoprotein B $(p<0.05)$. Reductions in triglycerides were greater with Inegy than rosuvastatin at the usual starting $(p=0.004)$ and next highest $(p=0.006)$ doses, and across all doses $(p<0.001)$. Increases in HDL-C, and decreases in high-sensitivity GRP (hsCRP) were similar between treatment groups. Safety profiles were comparable for both treatments; however, the percentage of patients with proteinuria was significantly higher following rosuvastatin treatment than Inegy, respectively, at $10 \mathrm{mg}$ vs $10 / 20 \mathrm{mg}(p=0.004)$ and $40 \mathrm{mg}$ vs $10 / 80 \mathrm{mg}(p<0.001)$. Overall, though the doses compared in this study were not equivalent on a milligram basis, the results provide clinically relevant information regarding the use of these drugs for initial therapy and for subsequent use at higher doses when appropriate.

\section{Long-term efficacy}

Two randomised double-blind studies have examined the long-term efficacy and safety of ezetimibe-simvastatin, 10/10, 10/20, 10/40 or $10 / 80 \mathrm{mg}$ vs monotherapy with simvastatin, $10,20,40$ or $80 \mathrm{mg}$, one for 48 weeks $^{33}$ the other for 26 weeks, ${ }^{34}$ for patients with primary hypercholesterolaemia $(n=433$ and $n=1104$ patients respectively). In the longer of these two studies patients underwent 6-week openlabel simvastatin run-in period and were then randomized to ezetimibe, $10 \mathrm{mg}$ or placebo in addition to simvastatin. The dose of simvastatin was then titrated according to achievement of the patient's LDL-G goal (NCEP ATP-II) ${ }^{b}$ at each study visit, or until the maximum dose of simvastatin $\left(80 \mathrm{mg}\right.$ ) was reached. ${ }^{33}$ This study revealed that reductions in LDL-C were maintained over the longer term. Thus, at week 12 (the first study visit prior to any statin dose titration) LDL-C levels were significantly lower in the ezetimibe-simvastatin group than in the simvastatin group $(-24$ vs $+3 \%$, respectively; $p<0.001)$, and these changes were maintained to the 48-week endpoint (Figure 4). As a

${ }^{\mathrm{b}}$ NGEP ATP-III LDL-C goals were not published at the time of this study. 
Figure 4. Percentage change in low-density lipoprotein cholesterol (LDL-C) within 48 weeks of ongoing treatment with ezetimibe-simvastatin or simvastatin monotherapy relative to the reductions achieved after 6 weeks' open-label treatment with simvastatin monotherapy (time 0 ). ${ }^{33}$

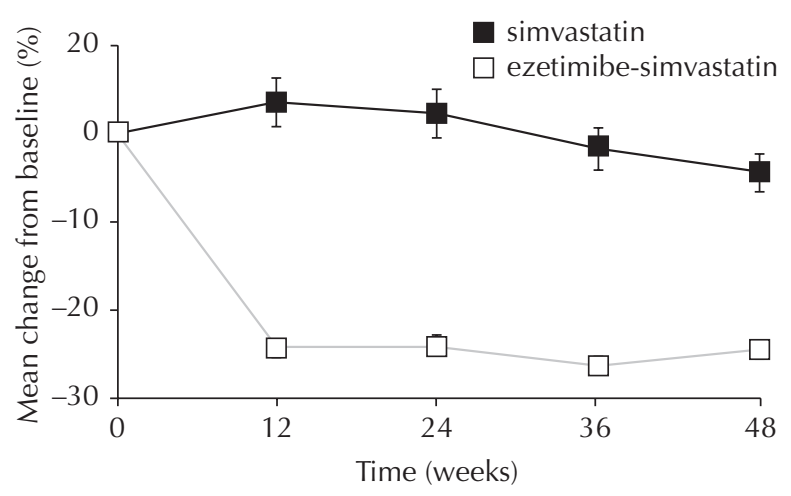

consequence, more patients receiving combination therapy achieved their ATP-II LDL-C goals than those receiving simvastatin monotherapy (59.6 vs 22.6\%; p-value not stated). In addition, other elements of the lipid profile were more favourably modified by combination therapy, with the exception of HDL-C. Importantly, there were fewer simvastatin dose increases in the group receiving ezetimibesimvastatin than those given simvastatin monotherapy. Thus, $48 \%$ of the ezetimibesimvastatin and $58 \%$ of the simvastatin monotherapy groups required dose titration, with a mean of 0.6 and 0.9 dose titrations per patient in each respective treatment group. The mean increase in dose for each titration was also lower in the ezetimibe-simvastatin then the simvastatin group (9.5 vs $16.6 \mathrm{mg}$ ). Finally, ezetimibe-simvastatin was reported to be well tolerated in this analysis. Therefore, in conclusion, ezetimibe-simvastatin provides meaningful reductions in LDL-C relative to simvastatin that are maintained over 1 year, and also reduces the number of dose titrations required to achieve LDL-G goals. Similar results were obtained in the shorter study, with more patients in the Inegy than the simvastatin group achieving LDL-C levels of $<2.6 \mathrm{mmol} / \mathrm{L}$ and the new, optimal treatment target of less than or equal to $1.8 \mathrm{mmol} / \mathrm{L}(p<0.001$ for both goals $){ }^{34}$

\section{Efficacy in clinical practice}

Two open-label, prospective, non-randomised, observational studies (study 1 with 19,194 patients, predominantly with CHD; study 2 with 19,484 patients, predominantly with diabetes, with the majority of patients already receiving statin therapy), were given ezetimibe-simvastatin, 10/10 mg (study 1: 15\% and study 2: 16\%), 10/20 $\mathrm{mg}$ (in 68\% each), 10/40 $\mathrm{mg}(12 \%$ and $10 \%$, respectively) or $80 \mathrm{mg}$ ( $1 \%$ and $1 \%$, respectively) as fixed-dose combinations over 3 months (dose decided at investigators' discretion). ${ }^{35}$ Mean LDL-C was reduced by $28 \%$ and $27 \%$ (study 1 and study 2) compared with baseline values (during which most patients were taking statin monotherapy). For study 1 and study 2, total cholesterol levels were decreased by $22 \%$ in each study, mean triglycerides by $16 \%$ and $17 \%$, respectively, and HDL-C was increased by $9 \%$ and $10 \%$, respectively. Adverse events were reported in $0.3 \%$ and $0.2 \%$ of patients, respectively. Thus, ezetimibe-simvastatin was effective and well tolerated under real-practice conditions in high-risk patients with CHD and/ or diabetes.

\section{Additional effects}

\section{Progression of atherosclerosis}

Currently, there is little direct evidence to demonstrate a pleiotropic effect of Inegy, though simvastatin has been shown to interfere with the formation of atherosclerotic lesions in large blood vessels, and may potentially retard the progression of atherosclerosis through a combination of anti-proliferative effects on smooth muscle, restoration of impaired endothelial activity, antithrombotic, antioxidant and anti-inflammatory effects. ${ }^{22}$ Animal models of atherosclerosis have demonstrated anti- 
atherogenic effects of both ezetimibe and simvastatin, given separately, ${ }^{11,22}$ but it is not clear whether the anti-atherogenic effect of ezetimibe is independent of lipid profile changes. A study involving 40 hypercholesterolaemic patients has suggested no benefit for ezetimibesimvastatin over simvastatin monotherapy in reducing arterial stiffness, though no firm conclusions can be drawn from a study of this size. ${ }^{36}$ The ENHANCE study (Ezetimibe and Simvastatin in Hypercholesterolaemia Enhances Atherosclerosis Regression) is an ongoing large-scale clinical trial designed to test whether the complementary mechanisms of action of ezetimibe and simvastatin provide any synergistic effects in terms of retarding the progression of atherosclerosis. ${ }^{37} \mathrm{~A}$ total of 725 patients with familial heterozygous hypercholesterolaemia, who are at a significantly heightened risk of developing premature atherosclerosis and cardiovascular disease, will be recruited into this randomised, double-blind clinical trial, and will be assigned to daily treatment with either Inegy, 10/80 mg, simvastatin, $80 \mathrm{mg}$, or placebo. Patients will be followed up over 2 years, and atherosclerotic progression in the carotid artery (using the carotid intima-media thickness as a marker of progression) will be evaluated in the different treatment groups.

\section{Effects on hsCRP}

As an independent marker of inflammatory risk, hsCRP is increasingly being used as a tool in the overall determination of a patient's cardiovascular risk profile, and one large study has examined this parameter in detail for patients given ezetimibesimvastatin or simvastatin monotherapy, ${ }^{38}$ using data from 1089 patients from two prospective clinical studies with a similar trial design. ${ }^{23,25}$ There was a doubling in the reduction of hsCRP associated with combination therapy relative to simvastatin monotherapy alone. ${ }^{38}$ Pooled data across individual doses of both combination and statin monotherapy revealed that plasma levels of hsCRP were reduced by $33.3 \%$ with ezetimibesimvastatin compared with a $14.3 \%$ reduction with simvastatin alone $(p<0.01)$. Incremental reductions in hsCRP were observed with increasing simvastatin dosage in both treatment groups. However, dose-by-dose comparisons revealed significantly greater effects for milligram equivalent dosages of the combination relative to simvastatin monotherapy $(p<0.05)$, with the reductions of hsCRP levels with simvastatin at 40 and $80 \mathrm{mg}$ similar to those elicited by the $10 / 10 \mathrm{mg}$ starting dosage of ezetimibe-simvastatin (26.9, 20.0 and 26.3\%, respectively). Moreover, changes to hsCRP levels occurred independently of effects on patients' lipid profile. Similar results have recently been reported based on the same clinical data, ${ }^{23,25}$ with the addition of data from the trial by Bays et al., 2004, ${ }^{24}$ thus also allowing a comparison with atorvastatin monotherapy. ${ }^{39}$ Ezetimibe-simvastatin was more effective at lowering LDL-C than atorvastatin when pooled across doses $(53.4 \%$ vs $45.3 \%$, respectively; $p<0.001$ ), but reductions in hsCRP were equivalent for these two groups, whether averaged across doses or for each milligramequivalent statin-dose comparison. ${ }^{39}$ In summary, combining ezetimibe with simvastatin significantly reduces hsCRP, potentiating the effects of simvastatin monotherapy on this marker, and suggests that in this population Inegy may further reduce inflammation and improve vascular stability compared with simvastatin, though not atorvastatin monotherapy.

\section{Efficacy in special patient populations Efficacy in patients with homozygous familial hypercholesterolaemia}

Patients with homozygous familial hypercholesterolaemia have excessively elevated plasma concentrations of LDL-C, placing them at high risk of atherosclerosis and cardiovascular events, and so require aggressive lipid-modifying therapy. The efficacy, safety and tolerability 
of different statin/ezetimibe combinations (including dosages equivalent to Inegy) has been assessed in a randomised, double-blind trial. ${ }^{40}$ A total of 50 patients with homozygous familial hypercholesterolaemia were randomised to 12 weeks' treatment with the following regimens: simvastatin or atorvastatin monotherapy (both at $80 \mathrm{mg} /$ day); ezetimibe (10 mg/day) plus simvastatin or atorvastatin (both at $40 \mathrm{mg}$ / day); or ezetimibe (10 mg/day) plus simvastatin or atorvastatin (both at $80 \mathrm{mg} /$ day). Patients were already receiving open-label atorvastatin or simvastatin (40 mg/day) at baseline, with or without LDL apheresis. The addition of ezetimibe to simvastatin or atorvastatin (40 or $80 \mathrm{mg} /$ day) provided significant reductions in LDL-C levels compared with statin monotherapy when given at the highest dose. Thus, LDL-C was reduced by $20.7 \%$ in the pooled ezetimibe/ statin combination group compared with $6.7 \%$ in those receiving a statin at $80 \mathrm{mg} /$ day $(p=0.007)$. When patients receiving the highdose combination (i.e. ezetimibe, $10 \mathrm{mg} /$ day, in combination with atorvastatin or simvastatin, 80 $\mathrm{mg} /$ day) were considered, the benefits were even greater, with an additional $20.5 \%$ reduction from baseline in LDL-C observed (-27.5 vs $-7.0 \%$; $p=0.0001)$. Thus, the high-dose ezetimibe/statin combination was about four-times as effective at reducing LDL-C as doubling the statin dose from 40 to $80 \mathrm{mg}$.

\section{Efficacy in patients with diabetic dyslipidaemia}

The dual mechanism of action of Inegy and its enhanced lipid-modifying effects may translate to more diabetic patients achieving the stringent lipid-level targets in diabetic populations compared with high-dose statin monotherapy. ${ }^{41}$ The thiazolidinediones are used for glycaemic control in type 2 diabetes, and also exert modest effects on the dyslipidaemic lipid profile, thus a double-blind, randomised trial of 214 patients with type 2 diabetes, who had been receiving ongoing treatment with a thiazolidinedione (rosiglitazone or pioglitazone) for at least 3 months, evaluated the relative lipid-modifying efficacy of adding ezetimibe to existing simvastatin therapy, compared with a doubling in the dose of simvastatin therapy. ${ }^{42}$ Patients received double-blind ezetimibe, 10 $\mathrm{mg} /$ day, or simvastatin, $20 \mathrm{mg} /$ day, added to existing open-label simvastatin, $20 \mathrm{mg} /$ day, for a period of 24 weeks. Levels of LDL-C were reduced by a significantly greater magnitude in the ezetimibe-simvastatin group compared with those receiving the double-dose simvastatin regimen (20.8 vs $0.3 \%$, respectively; $p<0.001$ ). In addition, combination treatment elicited significant incremental reductions in the nonHDL-C, VLDL-G and apolipoprotein B fractions compared with a doubling in the dose of simvastatin, though there were no significant differences between the two groups with respect to HDL-C and triglyceride levels.

Both treatment regimens were well tolerated, and importantly, the addition of ezetimibe to existing simvastatin treatment did not result in any deterioration in glycaemic control afforded by oral antidiabetic therapy.

A similar double-blind trial, also in patients with type 2 diabetes, investigated the effect of doubling the dose of atorvastatin from 10 to $20 \mathrm{mg}(\mathrm{n}=219)$, or switching from atorvastatin, $10 \mathrm{mg}$, to ezetimibe-simvastatin, $10 / 20 \mathrm{mg}$ $(\mathrm{n}=222)$, or ezetimibe-simvastatin, $10 / 40 \mathrm{mg}$ $(\mathrm{n}=222) .{ }^{43}$ Greater reductions in LDL-C were achieved by switching to ezetimibe-simvastatin, $10 / 20 \mathrm{mg}(26.2 \%)$ or $10 / 40 \mathrm{mg}(30.1 \%)$, than by doubling the dose of atorvastatin to $20 \mathrm{mg}(8.5 \%)$ $(p \leq 0.001)$. Moreover, the proportions of patients achieving LDL-C levels of less than $2.5 \mathrm{mmol} / \mathrm{L}$ were greater for ezetimibe-simvastatin, 10/20 $\mathrm{mg}(90.5 \%)$ and $10 / 40 \mathrm{mg}(87.0 \%)$, than with atorvastatin, $20 \mathrm{mg}(70.4 \%)(p \leq 0.001)$.

Similar dose regimens (with the addition of an atorvastatin, $40 \mathrm{mg}$ group) have also been evaluated in a large group of patients with type 2 diabetes $(n=1229)$, and again showed 
significantly lower LDL-C levels with Inegy, $10 / 20 \mathrm{mg}(53.6 \%)$, than atorvastatin, 10 or 20 $\mathrm{mg}(38.3 \%$ and $44.6 \%$, respectively; $p<0.001$ for both comparisons), and with Inegy, 10/40 $\mathrm{mg}$, than atorvastatin, $40 \mathrm{mg}(57.6 \%$ vs $50.9 \%$, respectively; $p<0.001) .{ }^{44}$ Furthermore, the proportion of patients achieving the stringent LDL-C target of $1.8 \mathrm{mmol} / \mathrm{L}$ was greater in the Inegy, $10 / 20 \mathrm{mg}$ group (59.7\%), than the atorvastatin, 10 or $20 \mathrm{mg}$ groups (21.5 and $35.0 \%$, respectively; $p<0.001$ ), and with the Inegy, $10 / 40 \mathrm{mg}$ group $(74.4 \%)$, than the atorvastatin, $40 \mathrm{mg}$ group $(55.2 \% ; p<0.001)$. Improvements in total cholesterol and HDL-C were also greater for the pooled Inegy than the pooled atorvastatin groups $(p \leq 0.001)$. There was a similar incidence of adverse events in the Inegy and the statin monotherapy treatment groups, with all treatments generally well tolerated.

\section{Efficacy in elderly patients}

A large post hoc analysis of clinical trial data has evaluated the relative lipid-modifying efficacy of ezetimibe-simvastatin (doses: 10/10, $10 / 20,10 / 40$ and 10/80 mg) compared with simvastatin monotherapy (10, $2040 \mathrm{or} 80 \mathrm{mg})$, in both older ( $\geq 65$ years; $n=763$ ) and younger $(<65$ years; $n=2320)$ adults with primary hypercholesterolaemia to determine whether there were any differential effects of treatment in patient groups stratified according to age. ${ }^{45} \mathrm{In}$ general, ezetimibe-simvastatin therapy elicited greater effects on the lipid profile compared with simvastatin monotherapy independently of patient age. More patients receiving ezetimibesimvastatin than simvastatin monotherapy achieved the LDL-C target of less than 2.6 $\mathrm{mmol} / \mathrm{L}(p<0.001)$, regardless of age sub-group $(77 \%$ vs $41 \%$ for patients aged $<65$ years and $85 \%$ vs $48 \%$ for patients aged $\geq 65$ years, respectively). Furthermore, all treatments were well tolerated, with a similar incidence of clinical and laboratory adverse events in the entire population and across the different groups stratified by age. Thus, ezetimibe-simvastatin appears to be an effective and well tolerated treatment option in older individuals with hypercholesterolaemia.

\section{Other special populations}

Women, in general, are not treated as aggressively as men with regard to the control of LDLC, particularly when established cardiovascular disease is present, despite women being at major risk of cardiovascular disease. ${ }^{46}$ Thus, a sub-group analysis of data from a number of clinical trials of ezetimibe added to various statins (including simvastatin) determined whether the advantages attributed to ezetimibe-simvastatin in these studies were equally realised by men and women. ${ }^{46}$ Data from a total of 1065 women and 796 men were analysed, and revealed that the beneficial effects of ezetimibe in combination with statins compared with statin monotherapy were comparable in women and men. In addition, the safety profiles of the different treatment regimens were similar between sexes. Another pooled retrospective analysis in a large population of patients with primary hypercholesterolaemia $(\mathrm{n}=3083)$ also showed consistent lipid-altering effects of ezetimibe-simvastatin across sexes, races, ages, baseline LDL-C levels and CHD status. ${ }^{47}$ Separate randomised, double-blind studies have also shown that ezetimibe-simvastatin is more effective in modifying hypercholesterolaemic lipid profiles than simvastatin monotherapy in African Americans $(\mathrm{n}=247),{ }^{48}$ patients admitted to hospital for a myocardial infarction $(n=60){ }^{49}$ statin-naïve patients with CHD $(\mathrm{n}=152) .{ }^{50}$ and patients with established chronic kidney disease $(\mathrm{n}=203) .^{51}$

\section{SAFETY AND TOLERABILITY}

\section{General adverse event profile}

The adverse event profile of Inegy is characteristic of its individual constituents, ezetimibe and simvastatin. The safety of ezetimibe in combination with simvastatin has 
been established across the 10/10-10/80 mg dose range in more than 3800 patients. ${ }^{17}$ The most commonly reported adverse events that occurred at a higher rate than placebo (regardless of causality) with Inegy include headache, upper respiratory tract infections and influenza-like illness, myalgia and pain in the extremities. In addition, the overall rates of treatment discontinuation were low, and the reasons for discontinuations were similar between all treatment groups in clinical trials. Finally, data from a longer-term clinical trial indicate that ezetimibe-simvastatin is well tolerated with up to 1 year of continuous treatment. ${ }^{33}$

\section{Skeletal muscle and liver effects}

Given the concern regarding the potential for myopathy with statin treatment, particularly at higher doses, it is pertinent to consider the effects of co-administration of ezetimibe and simvastatin.
From controlled clinical trial data, the incidence of clinically important (i.e. at least three-times the upper limit of normal [ULN]) elevations in the liver enzymes (aspartate aminotransferase [AST] and aminoalanine transferase [ALT]) was approximately $1.7 \%$ in patients treated with ezetimibe in combination with simvastatin. ${ }^{17}$ These increases were generally asymptomatic and were not associated with any adverse hepatic events such as cholestasis or jaundice. ${ }^{9}$ In general, levels of these transaminases returned to normal after treatment discontinuation. In results pooled from 17 clinical trials, and involving 4558 patients given Inegy, the incidence of myopathy (defined as symptomatic CK $\geq 10 \times \mathrm{ULN}$ ) was $0.04 \%$ (compared with $0.08 \%$ in the 2563 patients given simvastatin monotherapy).$^{52}$ Furthermore, myopathy and rhabdomyolysis have occurred only very rarely in Inegy post-marketing reports $(<1: 10,000) \cdot{ }^{41}$

\section{KEY POINTS}

- Inegy, consisting of ezetimibe and simvastatin, is available in a variety of doses, allowing physicians to tailor dosage for each patient to enable them to achieve their individual LDL-C goals.

- Inegy has a dual mechanism of action - inhibition of dietary and biliary cholesterol from the intestine (via the ezetimibe constituent) and inhibition of cholesterol biosynthesis in the liver (via the simvastatin component).

- Ezetimibe-simvastatin provides significantly greater reductions in LDL-C than simvastatin and atorvastatin monotherapy across their respective dose ranges, when compared at milligram equivalent dosages, and in many cases at higher statin doses. Inegy also lowers LDL-C levels to a greater extent than rosuvastatin at their respective starting, middle and maximal doses.

- The superior LDL-C-lowering effects of ezetimibe-simvastatin translate into significantly more patients achieving their LDL-C treatment goals than with statin monotherapy, including the most stringent LDL-C goal for very high-risk patients.

- Inegy is generally well tolerated, with an adverse event profile typical of the individual constituents of the combination. The most commonly reported drug-related adverse events in clinical trials are headache, upper respiratory tract infections and influenza-like illness, myalgia and pain in the extremities.

- Inegy may be particularly useful for patients who are unable to tolerate high doses of statin monotherapy, and those who have been unable to attain their LDL-C goals despite aggressive statin monotherapy. Highrisk patients with CHD or CHD risk equivalents (such as those with diabetes) may also derive particular benefit from Inegy 


\section{REFERENCES}

1 Grundy SM, Gleeman JI, Merz CN et al. Implications of recent clinical trials for the National Cholesterol Education Program Adult Treatment Panel III Guidelines. 7 Am Coll Cardiol 2004; 44: 720-32.

2 British Heart Foundation (BHF). Coronary Heart Disease Statistics 2007. Available from www.heartstats.org.

3 Rosamond W, Flegal K, Friday G et al. Heart disease and stroke statistics-2007 update: a report from the American Heart Association Statistics Committee and Stroke Statistics Subcommittee. Circulation. 2007 Feb 6;115(5): e69-171.

4 MRC/BHF Heart Protection Study of cholesterol lowering with simvastatin in 20,536 high-risk individuals: a randomised placebo-controlled trial. Lancet 2002; 360: 7-22.

5 Randomised trial of cholesterol lowering in 4444 patients with coronary heart disease: the Scandinavian Simvastatin Survival Study (4S). Lancet 1994; 344: 1383-9.

6 Pearson TA, Laurora I, Chu H, Kafonek S. The lipid treatment assessment project (L-TAP): a multicenter survey to evaluate the percentages of dyslipidemic patients receiving lipid-lowering therapy and achieving low-density lipoprotein cholesterol goals. Arch Intern Med 2000; 160: 459-67.

7 Third Report of the National Cholesterol Education Program (NCEP) Expert Panel on Detection, Evaluation, and Treatment of High Blood Cholesterol in Adults (Adult Treatment Panel III) final report. Circulation 2002; 106: 3143-421.

8 NICE. Ezetimibe for the treatment of primary (heterozygousfamilial and non-familial) hypercholesterolaemia. Technology appraisal guidance 132. November 2007. www.nice.org.uk

9 Murdoch D, Scott LJ. Ezetimibe/Simvastatin: a review of its use in the management of hypercholesterolemia. Am $\mathcal{F}$ Cardiovasc Drugs 2004; 4: 405-22.

10 Brown WV. Cholesterol absorption inhibitors: defining new options in lipid management. Clin Cardiol. 2003 Jun; 26(6): 259-64.

11 Chambers SR. Drug review - ezetimibe. Drugs in Context 2003; 1: 15-32.

12 Davidson MH, Ballantyne CM, Kerzner B et al. Efficacy and safety of ezetimibe coadministered with statins: randomised, placebo-controlled, blinded experience in 2382 patients with primary hypercholesterolemia. Int 7 Clin Pract 2004; 58: 746-55.

13 Kroom K. Ezetimibe - a clinically effective and a costeffective treatment option for dyslipidaemia. Drugs in Context 2008; 4: 85-104

14 Migoya EM, Bergman A, Hreniuk D et al. Bioequivalence of an ezetimibe/simvastatin combination tablet and coadministration of ezetimibe and simvastatin as separate tablets in healthy subjects. Int 7 Clin Pharmacol Ther 2006; 44: 83-92.

15 Altmann SW, Davis HR, Jr., Zhu LJ et al. Niemann-Pick C1 Like 1 protein is critical for intestinal cholesterol absorption. Science 2004; 303: 1201-4.

16 Knopfel M, Davies JP, Duong PT et al. Multiple plasma membrane receptors but not NPG1L1 mediate high-affinity, ezetimibe-sensitive cholesterol uptake into the intestinal brush border membrane. Biochim Biophys Acta 2007; 1771: 1140-7.
17 MSD-SP Ltd. Inegy tablets. Summary of product characteristics. July 2007.

18 Santosa S, Varady KA, AbuWeiss S et al. Physiological and therapeutic factors affecting cholesterol metabolism: does a reciprocal relationship between cholesterol absorption and synthesis really exist? Life Sci. 2007 Jan 16; 80(6): 505-14.

19 Kosoglou T, Statkevich P, Johnson-Levonas AO et al. Ezetimibe: a review of its metabolism, pharmacokinetics and drug interactions. Clin Pharmacokinet 2005; 44: 467-94.

20 Kosoglou T, Meyer I, Veltri EP et al. Pharmacodynamic interaction between the new selective cholesterol absorption inhibitor ezetimibe and simvastatin. Br 7 Clin Pharmacol 2002; 54: 309-19.

21 Flores NA. Ezetimibe + simvastatin (Merck/ScheringPlough). Curr Opin Investig Drugs 2004; 5: 984-92.

22 Bull E. Drug review - simvastatin. Drugs in Context 2004; 1(Part B): 257-96.

23 Davidson MH, McGarry T, Bettis R et al. Ezetimibe coadministered with simvastatin in patients with primary hypercholesterolemia. 7 Am Coll Cardiol 2002; 40: 2125-34.

24 Bays HE, Ose L, Fraser N et al. A multicenter, randomized, double-blind, placebo-controlled, factorial design study to evaluate the lipid-altering efficacy and safety profile of the ezetimibe/simvastatin tablet compared with ezetimibe and simvastatin monotherapy in patients with primary hypercholesterolemia. Clin Ther 2004; 26: 1758-73.

25 Goldberg AC, Sapre A, Liu J, Capece R, Mitchel YB. Efficacy and safety of ezetimibe coadministered with simvastatin in patients with primary hypercholesterolemia: a randomized, double-blind, placebo-controlled trial. Mayo Clin Proc 2004; 79: 620-9.

26 Feldman T, Koren M, Insull W, Jr. et al. Treatment of highrisk patients with ezetimibe plus simvastatin co-administration versus simvastatin alone to attain National Cholesterol Education Program Adult Treatment Panel III low-density lipoprotein cholesterol goals. Am 7 Cardiol 2004; 93: 1481-6.

27 Brohet C, Banai S, Alings AM et al. LDL-C goal attainment with the addition of ezetimibe to ongoing simvastatin treatment in coronary heart disease patients with hypercholesterolemia. Curr Med Res Opin 2005; 21: 571-8.

28 Farnier M, Volpe M, Massaad R, Davies MJ, Allen C. Effect of co-administering ezetimibe with on-going simvastatin treatment on LDL-C goal attainment in hypercholesterolemic patients with coronary heart disease. Int 7 Cardiol 2005; 102: 327-32.

29 McKenney J, Ballantyne CM, Feldman TA et al. LDL-C goal attainment with ezetimibe plus simvastatin coadministration vs atorvastatin or simvastatin monotherapy in patients at high risk of CHD. MedGenMed 2005; 7: 3.

30 Ballantyne CM, Blazing MA, King TR, Brady WE, Palmisano J. Efficacy and safety of ezetimibe co-administered with simvastatin compared with atorvastatin in adults with hypercholesterolemia. Am $\mathcal{F}$ Cardiol 2004; 93: 1487-94.

31 Ballantyne CM, Abate N, Yuan Z, King TR, Palmisano J. Dose-comparison study of the combination of ezetimibe and simvastatin (Vytorin) versus atorvastatin in patients with hypercholesterolemia: the Vytorin Versus Atorvastatin (VYVA) study. Am Heart 7 2005; 149: 464-73. 
32 Catapano AL, Davidson MH, Ballantyne CM et al. Lipidaltering efficacy of the ezetimibe/simvastatin single tablet versus rosuvastatin in hypercholesterolemic patients. Curr Med Res Opin 2006; 22: 2041-53.

33 Masana L, Mata P, Gagne C et al. Long-term safety and tolerability profiles and lipid-modifying efficacy of ezetimibe coadministered with ongoing simvastatin treatment: a multicenter, randomized, double-blind, placebo-controlled, 48-week extension study. Clin Ther 2005; 27: 174-84.

34 Ose L, Johnson-Levonas A, Reyes R et al. A multi-centre, randomised, double-blind 14-week extension study examining the long-term safety and efficacy profile of the ezetimibe/ simvastatin combination tablet. Int 7 Clin Pract 2007; 61: 1469-80.

35 Hildemann SK, Barho C, Karmann B, Darius H, Bestehorn K. Dual cholesterol inhibition with ezetimibe/simvastatin in pre-treated hypercholesterolaemic patients with coronary heart disease or diabetes mellitus: prospective observational cohort studies in clinical practice. Curr Med Res Opin 2007; 23: 713-9.

36 Efrati S, Averbukh M, Dishy V et al. The effect of simvastatin, ezetimibe and their combination on the lipid profile, arterial stiffness and inflammatory markers. Eur 7 Clin Pharmacol 2007; 63: 113-21.

37 Kastelein JJ, Sager PT, de Groot E, Veltri E. Comparison of ezetimibe plus simvastatin versus simvastatin monotherapy on atherosclerosis progression in familial hypercholesterolemia. Design and rationale of the Ezetimibe and Simvastatin in Hypercholesterolemia Enhances Atherosclerosis Regression (ENHANCE) trial. Am Heart 7 2005; 149: 234-9.

38 Sager PT, Capece R, Lipka L et al. Effects of ezetimibe coadministered with simvastatin on C-reactive protein in a large cohort of hypercholesterolemic patients. Atherosclerosis 2005; 179: 361-7.

39 Pearson T, Ballantyne C, Sisk C et al. Comparison of effects of ezetimibe/simvastatin versus simvastatin versus atorvastatin in reducing C-reactive protein and low-density lipoprotein cholesterol levels. Am f Cardiol 2007; 99: 1706-13.

40 Gagne C, Gaudet D, Bruckert E. Efficacy and safety of ezetimibe coadministered with atorvastatin or simvastatin in patients with homozygous familial hypercholesterolemia. Circulation 2002; 105: 2469-75.

41 Kastelein JJ, Sankatsing RR. Ezetimibe/simvastatin (INEGY) in the treatment of hyperlipidaemia. Int $f$ Clin Pract 2005; 59: 1464-71.

42 Gaudiani LM, Lewin A, Meneghini L et al. Efficacy and safety of ezetimibe co-administered with simvastatin in thiazolidinedione-treated type 2 diabetic patients. Diabetes Obes Metab 2005; 7: 88-97.
43 Constance C, Westphal S, Chung N et al. Efficacy of ezetimibe/simvastatin 10/20 and 10/40 mg compared with atorvastatin $20 \mathrm{mg}$ in patients with type 2 diabetes mellitus. Diabetes Obes Metab 2007; 9: 575-84.

44 Goldberg RB, Guyton JR, Mazzone T et al. Ezetimibe/ simvastatin vs atorvastatin in patients with type 2 diabetes mellitus and hypercholesterolemia: the VYTAL study. Mayo Clin Proc 2006; 81: 1579-88.

45 Feldman T, Davidson M, Shah A et al. Comparison of the lipid-modifying efficacy and safety profiles of ezetimibe coadministered with simvastatin in older versus younger patients with primary hypercholesterolemia: a post hoc analysis of subpopulations from three pooled clinical trials. Clin Ther 2006; 28: 849-59.

46 Bennett S, Sager P, Lipka L et al. Consistency in efficacy and safety of ezetimibe coadministered with statins for treatment of hypercholesterolemia in women and men. 7 Womens Health (Larchmt) 2004; 13: 1101-7.

47 Ose L, Shah A, Davies MJ et al. Consistency of lipid-altering effects of ezetimibe/simvastatin across gender, race, age, baseline low density lipoprotein cholesterol levels, and coronary heart disease status: results of a pooled retrospective analysis. Curr Med Res Opin 2006; 22: 823-35.

48 Rodney RA, Sugimoto D, Wagman B et al. Efficacy and safety of coadministration of ezetimibe and simvastatin in African-American patients with primary hypercholesterolemia. 7 Natl Med Assoc 2006; 98: 772-8.

49 Chenot F, Montant PF, Marcovitch O et al. Co-administration of ezetimibe and simvastatin in acute myocardial infarction. Eur f Clin Invest 2007; 37: 357-63.

50 Patel JV, Hughes EA. Efficacy, safety and LDL-C goal attainment of ezetimibe $10 \mathrm{mg}$-simvastatin $20 \mathrm{mg}$ vs. placebo-simvastatin $20 \mathrm{mg}$ in UK-based adults with coronary heart disease and hypercholesterolaemia. Int 7 Clin Pract 2006; 60: 914-21.

51 Landray M, Baigent C, Leaper C et al. The second United Kingdom Heart and Renal Protection (UK-HARP-II) Study: a randomized controlled study of the biochemical safety and efficacy of adding ezetimibe to simvastatin as initial therapy among patients with CKD. Am F Kidney Dis 2006; 47: 385-95.

52 Davidson MH, Maccubbin D, Stepanavage M, Strony J, Musliner T. Striated muscle safety of ezetimibe/simvastatin (Vytorin). Am 7 Cardiol 2006; 97: 223-8.

Correspondence:

Stephen I'Anson, Just Medical Media Ltd, 11 Redgrove Park, Cheltenham, Gloucestershire, GL51 6QY, UK. Email: publisher@justmedicalmedia.com. 